\title{
Heterotopias e trajetividades: lugares para as diferenças nas subjetividades nômades
}

\section{Heterotopias and trajectivities: places for differences in nomad subjecitivities}

https://doi.org/10.34112/2317-0972a2018v36n73p119-134

\section{Alexandre Filordi de Carvalho ${ }^{1}$}

Resumo: A partir de duas experiências cinematográficas, Omar e The giver (O doador de memória) como agenciamentos de signos da arte, busca-se, ao longo do texto, explorar a ideia de que heterotopias e trajetividades são noções importantes para se pensarem as diferenças no sentido de experiências de subjetividades nômades. Para tanto, é preciso combater a máquina de produção de subjetividades sedentárias. Dessa maneira, em um primeiro momento, desde uma hipótese proustiana, intenta-se entender o que são experiências com as heterotopias e as trajetividades, sobretudo a partir do filme Omar. Em segundo lugar, a partir de uma questão extraída do filme The giver, explora-se como o campo problematizador das diferenças pode ser afirmado entre a confrontação da máquina de produção de subjetividade sedentária e a máquina de produção de subjetividade nômade.

Palavras-chave: Heterotopias; diferença; nomadismo.

ABSTRACT: Taking two cinematographic experiences as assemblages of the signs of art, Omar and The Giver, this article explores the idea that hererotopias and trajectivities are relevant notions to think of differences toward the experiences of nomad subjectivities. In order to do so, it is necessary to fight against the production machine of sedentary subjectivities. Therefore, on one hand, the text proposes a comprehension of the experiences as

1. Universidade Federal de São Paulo, Guarulhos, SP, Brasil. 
heterotopias and trajectivities, especially in the case of the Omar movie. On the other hand, from The Giver, the text explores how the fields of the differences can be asserted between the confrontation of the production machine of sedentary subjectivity and the production machine of nomad subjectivity.

KEYWORDS: Heterotopias; difference; nomadism.

Outros circulam, procurando familiaridades proveitosas. (RAMOS, 2013, p. 21)

\section{Heterotopias e trajetividades: o caso de OMar}

Close em um olhar congelado e profundo. De costas para um muro, Omar aguarda três carros passarem. Volta-se para o muro e pega na corda fixada desde o seu topo, que escorre abaixo. O muro é alto, mais ou menos de proporções quíntuplas com relação ao tamanho da personagem: um homem feito. Omar escala o muro com destreza. Ao sobrepassá-lo, um tiro quase o acerta. Ele se joga ao chão. Correndo em disparada, entra em becos e ruelas, seguindo, como um rato de experimento em um labirinto estreito, uma rota pela qual se deixa perder. De repente, Omar para. Olha para trás, sorvendo o ar, o mesmo ar de sua sobrevivência. É o mesmo olhar do início da cena. Omar, porém, já não é o mesmo. Ele passou o muro, e continua, apesar de tudo, vivo, mas doravante de outro jeito. Omar cumpriu o seu trajeto e, com ele, faz a sua heterotopia (ABU-ASSAD, 2013, o':36").

A cena se repetirá por algumas vezes ao longo do filme homônimo do personagem, reduplicando as proporções de um trajeto a se adensar e a se complicar cada vez mais para Omar. As suas experiências com as rotas, os espaços, os muros, as idas e vindas em terras distintas vão, concomitantemente, dissolvendo as certezas de Omar quanto ao sujeito que pensava ser e, sobretudo, aos planos existenciais outrora concebidos para si, bem como as expectativas futuras que tinha em função desses mesmos planos. A vida de Omar altera-se profundamente em função de sua trajetividade e dos lugares diferentes com os quais passa a coexistir.

Que muro é esse? Onde está situado? Ele separa e delimita o quê? É uma prisão? Que representação há em torno desse muro: muro de Berlim, muro de um condomínio, muro estadunidense-mexicano, muro gaza-israelo-cisjordânio, muro de um hospício, muro de um hospital, muro da escola, muro de uma penitenciária? 
Que muro é esse? Que tipos de vias estreitas se conjugam e coexistem-se com a função-muro? Ao escalar o muro e percorrer as ruelas, necessariamente Omar foge? Escapa ou entra? Foge ou penetra?

Certamente, se não há uma mínima localização desses aspectos, o leitor pouco consegue inferir da cena. Mas esse é o objetivo aqui, pois heterotopia e trajetividade não dizem respeito à interpretação que se pudesse dar à cena; nem às reduções explicativas capazes de minimizar a potencialidade de seus signos a uma ordem explicadora: o muro quer dizer isso, ele ensina que..., etc. etc.; tampouco a cena representa um fato, um episódio, um marco fechado ao longo do filme. A cena pertence a Omar; a cena é coextensão tempo-espacial da dupla experiência com a heterotopia e com a trajetividade daquele sujeito: diz respeito a ele, é dele, e para ele; a cena é um lance, uma aposta, em meio a tantas outras possibilidades, de conviver com uma trajetividade e de se fazer no lugar outros lugares, como é próprio da heterotopia. E toda trajetividade é uma angústia, pois coloca o sujeito que a experimenta diante de uma abertura espacial que não é mais a relação impositiva do espaço, mas a escolha de uma espacialidade, quer dizer, de um fazer-se e constituir-se no trajeto cuja consistência é a de um fluxo nômade a se refazer conforme o refazer-se com o próprio trajetificar-se.

Com efeito, é preciso considerar a heterotopia como uma estratégia invasiva na política do espaço e também na política do tempo. Em toda heterotopia repousa uma heterocronia: não se vive a mesma temporalidade nos mesmos espaços; não se vive a mesma espacialidade na mesma temporalidade. $\mathrm{O}$ muro a segregar, a delimitar, a demarcar o bem privado, também pode ser objeto de contenção, de encarceramento, de exclusão, de cisão, de controle de fluxos de bens, de pessoas, de animais. Qualquer indivíduo de dentro do muro pode ser alguém distante e inacessível para quem estiver de fora. $\mathrm{O}$ muro pode se transformar, ainda sob a égide de cada uma de suas funções, em arte, muro de protesto, muro de mictório, muro amparador de bêbados, muro ponto de pedintes, muro apoio de revista policial, muro recanto da trepadeira, muro das lamentações, muro ideológico, e sucessivamente. Estaríamos assim diante de uma experiência de contraespaço. A heterotopia é um contraespaço em um contratempo. Por isso mesmo, ela produz outros trajetos e, por eles e com eles, maneiras outras, diferentes, de se fazer sujeito. O que ocorre sob o influxo da heterotopia pode acabar sendo deslocado de uma função normalizadora, dando lugar ao imprevisível, mas também ao que não é desejado pela lógica daquele mesmo espaço. Assim nasceriam as utopias, por exemplo. Mas assim também nasceram os asilos, os manicômios, os quartéis, as escolas, os hospitais: utopia de resgate e de 
cura, utopia de aperfeiçoamento humano num quadriculado de muro que se reduplicava de desconstrução em desconstrução de funções para forjar outras.

Para Foucault (2009), a heterotopia poderia ser exemplificada pelas estratégias que as crianças têm de assaltar a lógica das funções e subvertê-las por completo e, por conseguinte, fazer transbordar os limites estabelecidos das hetero-utopias.

Esses contra-espaços, essas utopias localizadas, as crianças conhecem perfeitamente. É o fundo do jardim, claro está, o celeiro, ou melhor ainda, a tenda dos índios armada no meio do celeiro, é também - na quinta-feira à tarde - a cama dos pais. Sobre esta cama se descobre o oceano, porque se pode ali nadar entre as cobertas; mas também é o céu, uma vez que se pode pular no colchão; é a floresta, porque ali se esconde; é a noite, já que é possível se tornar um fantasma entre os lençóis; é o prazer, e enfim, na volta dos pais a punição. (FOUCAULT, 2009, p. 24)

Toda essa dimensão se coloca para os sujeitos históricos e singulares, pois a experiência de cada um não prescinde dos trajetos e dos lugares que, forçosamente, compõem suas respectivas consistências existenciais. Existir é estar em um trajeto, e um trajeto é uma aventura política do modo de existir. A trajetividade, ademais, também é uma passagem constante, um deslizamento irrecuperável posto entre as condições objetivas do existir e as suas condições subjetivas, quer dizer, entre a maneira pela qual um dado objetivo, como, por exemplo, a escassez, é tratado subjetivamente por alguém, conforme o aspecto trajetivo do fazer-se com e na escassez.

Virilio (1993, p. 107), responsável por dar tratamento conceitual à trajetividade, argumenta, de maneira sobeja, o seguinte:

Entre o subjetivo e o objetivo parece não haver lugar para o "trajetivo", este ser do movimento do aqui até $\mathrm{o}$ além, de um até o outro, sem o qual jamais teremos acesso a uma compreensão profunda dos diversos regimes de percepção do mundo que se sucederam ao longo dos séculos, regimes de visibilidade das aparências ligados à história das técnicas e das modalidades de deslocamento, das comunicações à distância, com a natureza da velocidade dos movimentos de transporte e da transmissão engendrando uma transmutação da "profundidade de campo" e, consequentemente, da espessura ótica do meio ambiente humano, e não apenas uma evolução dos sistemas migratórios ou do povoamento de determinada região do planeta. 
Ora, tais termos pesam na compreensão da trajetividade por realçar a conexão de abertura e de deslizamento presente entre o "aqui e o além". Não à toa, na experiência de trajetividade se consome a heterotopia, e certamente vice-versa. Assim, encontram-se em jogo as formas pelas quais os regimes de "percepção do mundo" se colocam em face de todo tipo de deslocamento possível de ser entendido, contemplado ou produzido. O trajetivo-heterotópico, com efeito, não é a redução objetiva de um espaço ao seu signo mundano ou à sua significação congelada. Tampouco é um aferente subjetivo a ignorar a instância objetiva do espaço. Mas é, ao mesmo tempo, o compósito do espaço objetivo e subjetivo com o intuito de produzir o que há de mais importante, naquele sentido de diferença deleuziana, no sujeito, a saber: a sua própria constituição de diferença com o seu trajeto, o seu lugar - o seu topos - e a sua trajetividade existencial como diferença.

Eis Proust (1958, p. 319) constituindo-se a partir de suas experiências de trajetivo-heterotópicas:

Desejaria tomar logo no dia seguinte o belo e generoso trem da uma e vinte e dois, cujo horário de partida eu não podia ler nos prospectos das companhias ferroviárias sem que o meu coração palpitasse: essa hora parecia abrir num ponto preciso da tarde uma saborosa incisão, um signo misterioso a partir do qual as horas desviadas, embora conduzissem à noite e à manhã seguintes, já não transcorreriam em Paris, mas sim numa das cidades por onde passava e entre as quais ele nos permitia fazer uma escolha; pois parava em Bayeux, Coutances, Vitré, Questanbert, Pontorson, Balbec, Lanion, Lamballe, Benodet, Pont-Aven, Quimperlé, e avançava magnificamente sobrecarregado de nomes que me oferecia e que eu não sabia, entre tantos, qual escolher, na impossibilidade de sacrificar um só que fosse.

Conta na trajetividade e na heterotopia essa abertura imponderável perante o objetivo. Numa tarde dada, Proust atreve-se a se deparar com uma "saborosa incisão", e um "signo misterioso" emerge. Ele se deixa deslizar não apenas em uma temporalidade, mas nos espaços, ou melhor ainda, nas terras cujos nomes são mais do que nomes de lugares, mas deslizamentos em face de certas escolhas conforme ele pôde "passar" pelos lugares. A passagem tornara-se, então para ele, o trajeto para outro lugar, para outra experiência de si mesmo.

Nem sempre, contudo, é assim. A relação com o espaço pode ser de um trajeto que não se trajetifica por deslizamentos, mas que se congela em uma finalidade 
prévia. Portanto, há formas distintas de trajetividades. Se Proust pegasse o trem pensando apenas em Balbec, toda possibilidade de fuga, de deslizamento, de experiência heterotópica estaria capturada em um mapa predefinido. Sair de $x$ para chegar a $y$. Esse não é o caso. Ele desejava é outra coisa. Ele desejava o "signo misterioso", ele desejava as ruelas de Omar, o deslizamento, os nomes, entre tantos, a escolher. É o meio que lhe interessava, aquele mesmo meio mencionado por Virilio como o "do aqui até o além", aquele "de um até o outro" movimento. O trajeto do ser nesse exemplo de Proust não é o do sedentário, isto é, no trajeto não prevalece "o sujeito e o objeto", ou "o movimento em direção ao imóvel, ao inerte, que caracteriza o 'civil' sedentário e urbano" (VIRILIO, 1993, p. 108). Ao contrário, nessa experiência "predomina o nômade, a trajetória do ser" (VIRILIO, 1993, p. 108). O mesmo está presente em Omar: as somas das trajetividades de Omar não esgotam a potencialidade de sua própria trajetividade heterotópica. Na mesma proporção que ele se constitui com ela, ele a transborda, pois o trajetivo pressupõe o escape, a fuga, o deslizamento, uma geolistese, heterotopias.

Um ponto, um espaço, um território, uma cercania, um local, uma urbanidade, um nome, uma cidade, uma terra. Do ponto de vista trajetivo-heterotópico nada disso é um, nem unificado e menos ainda significado. Na trajetividade e na heterotopia tudo está por percorrer, já que ambas pressupõem deslizamentos múltiplos. Ademais, ambas se tornam, por conseguinte, um signo aberto para experiências múltiplas de transdeslocamentos e, portanto, para experiências com a diferença. Por que ser assim? Porque, argumenta Deleuze, "erramos quando acreditamos nos fatos: só há signos. Erramos quando acreditamos na verdade: só há interpretações. O signo tem um sentido sempre equívoco, implícito e implicado" (DELEUZE, 2010, p. 86). Em outros termos, ver a cena do trajeto de Omar como trajetividade e heterotopia implica saber de duas coisas. De um lado, há o trajeto de Omar, impossível de ser vivido a não ser por ele mesmo. Em tal perspectiva, ele se compõe e se recompõe em múltiplas experiências, e conforme vivencia os seus trajetos, que poderiam ser outros além de aqueles, faz-se diferente, faz-se múltiplo a partir de si mesmo. De outro lado, há o espectador. Este apenas recompõe a trajetividade de Omar com afetos, com percepção própria, com expectativa, com juízos de valores, com a sua peculiar constituição trajetificada, afetando-se a si mesmo, impedido, porém, de viver como Omar. Isso, contudo, acaba sendo um convite inspirador à experiência da alteridade: o que fazer de minha trajetividade quando me deparo com a trajetividade do outro? O mesmo poderia ser dito para Proust e o leitor de Proust. 
Sendo assim, habitar um território, inclusive existencial, não é fixar-se nele, é por ele passar, deslizando-se afora; o espaço de seu(s) lugar(es) é uma composição de deslizamentos experimentados, conforme se espacializa o trajeto do sujeito sem a pretensão de reduzir-se a um território com fronteiras delimitadas, fazendo dele prisão de trajetividades e de heterotopias. Habitar o espaço é convocar signos trajetivo-heterotópicos. Omar entrando em becos e em ruelas. Proust deslizando na saborosa incisão de um signo misterioso. Ambos estão correndo de um centro referente de captura: Omar desvia-se da bala, mas também de olhares; Proust parte de Paris. Isso é próprio da trajetividade e da heterotopia, além de o descolar-se para além do modelo, já que "segundo o modelo legal, não paramos de nos reterritorializar num ponto de vista, num domínio, segundo um conjunto de relações constantes" (GUATTARI, 1992, p. 40).

O muro de Omar é o muro dos espaços, dos quadriculamentos, dos quarteirões, dos bairros, dos lugares referentes e referenciados; o muro é o grande centro e é a periferia, pontos cardeais na e da locomoção urbana; mas também é o espaço temporalizado pela locomoção, pelo deslocamento, pelo engarrafamento; o muro compõe as habitações e os seus de dentro, os seus interiores com demarcações entre exteriores: são fronteiras, limites estabelecidos, rotas traçadas, caminhos mapeados, signos significados em coordenadas precisas. Ao saltar o muro e perder-se na fuga, Omar dá azo à trajetividade e à heterotopia. Ele apenas vai, segue, foge, passa pelo espaço, sabendo que o espaço também passa por ele. A trajetividade inicial apenas prenuncia outras trajetividades de jogo aberto e desdobradas pelo silêncio profundo de um olhar que o espectador mal ousa compreender. O labirinto da cena é o labirinto da trajetividade. E de ambos os casos emergirão dissoluções sucessivas de identidades, fugas, superações de outros muros, traições, línguas e incompreensões, morte, vida, espaços chinfrados, estrangeiridades, rupturas, viagens, trajetos, projéteis, choros, abraços, traços de trajetividades deslizantes, terras heterotópicas incapturáveis pelo sentido da terra e por um nome qualquer - diferenças experimentadas.

LUGARES PARA AS DIFERENÇAS: ENTRE A MÁQUINA DE PRODUÇÃo DE SUBJETIVIDADE NÔMADE E SEDENTÁRIA

"A partir das ruinas, as comunidades foram erguidas. Protegidas pelos limites. Todas as lembranças do passado foram apagadas"(NOYCE, 2014, o':17"). O texto surge projetado na tela escura. São as considerações iniciais, ou a linha-mestra do filme The giver, 
traduzido em português por $O$ doador de memórias. Em seguida, os primeiros planos, em sobrevoo dinâmico, das comunidades mencionadas. Uma imagem basta para uma compreensão: trata-se de um conjunto ordenado de casas e de ruas em meio a uma vegetação bem distribuída. Prevalece o tom de um sépia claro em toda a cena, aliás, como em boa parte do filme. Vê-se com clareza o realce na padronização bem arquitetada, tanto da cidade erguida quanto da tonalidade cinematográfica. Concomitante ao surgimento desse plano, uma voz em off redesdobra os termos inicias, dizendo:

Após as ruínas, nós recomeçamos, criando uma nova sociedade. Uma com verdadeira igualdade. As regras foram os elementos básicos dessa igualdade. Nós aprendemos quando crianças regras como: "usar discurso claro"; "usar suas roupas designadas"; "tome seu remédio pela manhã" - injetável; "obedeça ao toque de recolher"; "nunca minta" (NOYCE, 2014, o':35").

Entre o sujeito indeterminado da frase projetada na tela escura, "a partir das ruínas, as comunidades foram erguidas" e o anúncio da voz em off de um sujeito coletivo, "após as ruínas, nós recomeçamos, criando uma nova sociedade", localiza-se uma máquina de produção de sedentarismo. Os efeitos dessa máquina, como se vê, não visam a heterotopia. As suas ações tampouco urdem uma trajetividade nômade. O prenúncio do desenrolar das cenas em The giver, desde a produção maquínica da localização das comunidades, supõe uma reconstrução sem sujeito, isto é, uma série de atividades de recomposição territorial, de suas dimensões e de suas finalidades sem a clareza de seus agentes: "a partir das cinzas das ruínas, as comunidades foram erguidas". Não distante desse contexto encontra-se a tônica dos limites e do apagamento da memória. A voz em off apenas remarca o pertencimento de si mesma e dos demais integrantes às comunidades reconstruídas como retomada do que já fora erguido de maneira indeterminada. Os espaços, os topoi, estão todos dados. Por não saber como se deu um novo princípio, e num jogo de palavras, por que os princípios de um território já demarcavam a sua geografia, tais sujeitos engajam-se em sua reconstrução: "após as ruínas, nós recomeçamos criando uma nova sociedade". Sociedade para a qual o fio da balança é a obediência às regras estabelecidas, visando a uma "verdadeira igualdade". Ações indeterminadas, porém, determinantes; engajamento no que foi traçado para o funcionamento da sociedade - ressalta-se o sujeito indeterminado -; soerguimento de limites, claro está, entendido como fronteira, demarcação, alfândega geopolítica de controle de entrada e de saída, imposição restritiva aos fluxos de trajetividade; apagamento da memória das relações com o espaço de outrora, logo, com todos os 
afetos e as percepções que remarcavam um certo pertencimento, como sustentava Arendt (2007), a um sentido de tradição; imposição de regras para os fluxos das ações dos sujeitos e, por conseguinte, cobrança de níveis de obediência; estabelecimento do princípio da igualdade como retentor de qualquer diferença, justificando, assim, o porquê dos limites, da dissolução da memória, das regras e da obediência; soerguimento da homotopia em detrimento da heterotopia. Esses elementos compõem a máquina de trajetividade dessa sociedade futurista, mas também compõem qualquer máquina de produção de subjetividade sedentária, uma vez que a função primordial desta máquina a de é impedir a produção de diferenças e de toda trajetividade nômade.

Extraído do pensamento de Deleuze e Guattari (2010, 2011a, 2011b), o conceito de máquina não traduz uma idealização ou uma abstração de ordem conceitual. A máquina é concreta e gera concretude, uma vez que ela é produtiva. Concebida dessa forma, a máquina intenta ir além, e antepor-se mesmo à ideia de representação. Quer dizer, a máquina não está presa a uma "classe mental", nos termos de Deleuze (2010), porque ela não é codependente das leis da linguagem. Ora, em toda representação prepondera o objetivismo de um signo: "relacionar um signo ao objeto que o emite, atribuir ao objeto o benefício do signo, é de início a direção natural da percepção ou da representação" (DELEUZE, 2010, p. 27). Os caminhos traçados em um mapa são signos de representações, pontos fechados que ligam, corretamente, a partida A ao destino B. Suas linhas (signos) devem estar em conformidade com a representação: estradas principais, estradas vicinais, estradas pavimentadas, estradas de terra, avenidas, ruas, becos, etc.

Se a máquina não se traduz em representação, por efeito lógico, a máquina também ultrapassa a ideia de fundamentação metafísica e de estrutura fundamental, pois toda máquina também está a gerar outras máquinas que podem diferenciar entre si, embora possam produzir o mesmo efeito. Por exemplo, a máquina burocrática é composta de infinitas outras máquinas menores para produzir os mesmos efeitos: cumprimento de etapas hierarquizantes, rituais de passagem, dependência de encaminhamentos, cumprimento de prazos, tudo isso estendido e presente do menor ou maior guichê de uma instituição qualquer. Toda máquina está conectada por phylums com outras máquinas.

Por exemplo, os espaços de fechamento da escola a permitir certas possibilidades de relações e de convivência, como o pátio, não é fundado pela escola. Tal espaço reativa linhas entremeadas, os seus phylums maquínicos, advindos das máquinas de produção 
de espacialidade dos antigos monastérios, dos conventos, dos asilos, dos sanatórios, das prisões, etc. Mas também da organização dos soldados romanos em decúrias, em centúrias, e sucessivamente ou, ainda, dos espaçamentos divisores dos signos feudais. (CARVALHO; CAMARGO, 2015, p. 109-110)

Isto posto, pode-se dizer que a máquina de produção de subjetividade sedentária é toda aquela que produz espaços e territórios agenciando fluxos intercomunicáveis de pertencimento às interioridades e às exterioridades. Numa ideia simples, em toda produção sedentária, sob tal horizonte, há segregação. A máquina de sedentarismo, dessa maneira, tem o intuito de gerar um tipo de produção a fazer sentido aos códigos de localização, de locomoção, de habitação, de mudança, de trânsito legalizado em um território qualquer; também ela produz identificações com margens de espaços ordenados para agenciar fluxos de idas e de vindas, que podem ser: de economia, de objetos, de pessoas, de símbolos abstratos (Meca, Compostela, Jerusalém, Lourdes, Aparecida), de veículos, e inclusive da própria mutação da terra (construção de barragens, demolição de uma encosta, abertura de um túnel, subtração de recursos geológicos), em outras palavras, um pleno "erguer e recomeçar" semelhante ao proposto em The giver.

Mas onde essa máquina principia e termina? Esse é outro aspecto interessante de toda máquina de produção de subjetividade, pois ela é tão antiga quanto a ramificação ancestral do homem. Desde que houve dominação sobre um ambiente para transformá-lo em habitat, a máquina produtora de sedentarismo disparou toda sorte de maquinismo. E desde o instante em que todo ambiente se geopolitizou, ela não cessou de produzir trajetividades maquinadas com fins sedentários, isto é, trajetividades controladas ou experiências com as homotopias, no lugar das heterotopias. Em outros termos, a máquina de produção de subjetividade sedentária vem se acoplando a todo tipo de máquina a fim de forjar contorno a uma produtividade territorial, e, em toda a sua extensão, modos precisos de existência por "extração de fluxos, separação de cadeias, repartição de partes" (DELEUZE; GUATTARI, 2010, p. 188). É assim que passam a existir limites, fronteiras, ações advindas de sujeitos indeterminados - porque o Estado exige -, apagamentos da memória com relação às mutações geopolíticas e as suas consequências, a imposição de regras e de obediência na relação vida-espaço-territorialidade.

Para tanto, a máquina de sedentarismo não prescinde de relações com outras máquinas. É o caso das máquinas sociais, ou seja, os equipamentos sociais, tais como: 
escola, igreja, partidos políticos, etc. Basta notar o que ocorre quando se trata de uma ocupação de um aparelho de ensino, de demarcação de terra indígena, de um movimento por reforma agrária ou por avanço desregrado na terra por parte dos agronegócios. O que se convoca? O que está em jogo? Que trajetos são possíveis? Que lugares são controlados, vigiados, assistidos? Sempre um ou mais equipamentos sociais estão aí envolvidos. Mas as máquinas sociais, por sua vez, atrelam-se às máquinas técnicas; essas se atrelam às máquinas abstratas. Assim, computadores, televisores, carros, smartphones, etc., de um lado, línguas, leis, linguagens informacionais, etc., de outro lado, são veiculados e vinculados às questões exemplificadas acima.

Por essas razões, a fala inicial em The giver convoca um sujeito indeterminado. É ao redor desse mesmo sujeito que limites, apagamentos da memória, regras e obediência visando à igualdade ganharão proporções de realidade. Por existirem as conexões na máquina produtora de sedentarismo com uma série de agenciamentos com outras máquinas, a sua produção acaba se reduzindo a um certo automatismo, próprio dos termos indeterminados, como se a ordem dos acontecimentos e dos espaços tivessem de ser tal como é. O que convoca à reflexão em tal máquina é justamente o ponto cego de toda a sua produção: o automatismo produtivo de ações sem sujeitos, de limites impositivos, de acontecimentos sem conexão com o passado ou com a memória, e ainda a imposição de cumprimento de regras de locomoção, de estilo de viver, de imposição espacial - do muro de Omar aos limites invisíveis de The giver.

No cenário atual, o espaço não está mais atrelado apenas a uma espacialidade, nem um território a uma mera circunscrição de medida (VIRILIO, 1993). Em ambos os casos, há uma intensidade de conexões que transborda o lugar, transformando-o em pontos geoinerciais, reduzindo a potência trajetiva e heterotópica a uma experiência de sedentarismo inercial, já que, com o avanço das máquinas técnicas, é possível cada vez mais "sair do lugar" sem dar um passo.

Em primeiro lugar, porque o que Virilio concebia como futuro, de forma acelerada, configurou-se como realidade para a atual experiência tempo-espacial:

[...] o controle do meio ambiente em tempo real prevalecerá sobre a organização do espaço real do território [...] [sob um] horizonte trans-aparente, fruto das telecomunicações, que permite vislumbrar a possibilidade inusitada de uma "civilização do esquecimento", sociedade de um "ao vivo" (live coverage) sem futuro e sem passado, posto que sem extensão, sem duração, sociedade intensamente "presente" aqui e ali, ou seja, sociedade telepresente em todo o mundo. (VIRILIO, 1993, p. 108. Grifos meus) 
Enquanto a trajetividade nômade permite um deslizamento, ou melhor, uma experiência de passagem entre espacialidades, um ir e vir incessante, sem fixação ou teleologia mapeada das ações, na máquina sedentária a trajetividade se fecha entre muros, isto é, entre limites. Mais do que isso, ela se fixa numa presentificação a bloquear devires nômades. Não sem sentido, a sociedade atual, a julgar pelos termos de Virilio, assenta-se perfeitamente nas mesmas condições das comunidades futuristas de The giver. Ao contrário do filme, porém, a civilização do esquecimento não precisa de injeções que apagam da memória as experiências com um passado vivido em outros territórios, mantendo tudo sob controle: ordem e obediência. Nessa civilização, o esquecimento é derivado de toda produção da máquina sedentária pela qual os sujeitos apenas passam, "sem futuro e sem passado". O passar, nesse caso, diferentemente daquele de Proust, é o conectar-se com fluxos fechados que intensificam apenas o presente. É assim, por exemplo, que comunidades inteiras são removidas em todo o mundo em função de construções gigantescas, como uma hidroelétrica; modificações geohumanas são feitas em função da indústria cultural ou ludo-cultural - jogos olímpicos, copas do mundo - exemplos ímpares da presentificação do gozo capitalista; povos autóctones demovidos ou até mesmo dizimados em função de explorações de recursos minerais. Em todo esse cenário, o poder da máquina sedentária repousa no fato de ser normalizada em função de como as máquinas técnicas e as máquinas abstratas forjam musculatura para o progresso humano.

Em segundo lugar, porque a “[...] forma urbana não é mais expressa por uma demarcação qualquer, uma linha divisória entre aqui e além, [tornando-se] a programação de um 'horário'” (VIRILIO, 1993, p. 11). Doravante, a máquina de produção de sedentarismo tem a capacidade de produzir espacialidade conjugada com temporalidade, fazendo que o deslizamento trajetivo esteja constrangido a uma mobilidade assertiva e coerente com o tempo que se tem. As possibilidades de experimentalismo com e nos espaços, como é peculiar à trajetividade, com efeito, tornam-se cada vez mais improváveis. E toda lógica espacial ganha contornos de eficiência para que ninguém perca tempo com o que não se pode perder tempo. Assim as comunidades são erguidas, assim passam a ser protegidas contra o caos e tudo que poderia fazer soçobrar a ordem estabelecida dos fluxos do ir e do vir: a polícia sobe o morro, o condomínio isola a pujança, o transporte coletivo transborda o miserável, à periferia não chega a água tratada, e tudo isso pode ser visto sem que se saia do lugar.

Tanto no primeiro como no segundo caso, há um desdobramento eficiente da inércia sobre a trajetividade e, claro está, um bloqueio incessante da heterotopia. Isso 
quer dizer que o sedentarismo se reatualiza de modo terminal: "a inércia tende a renovar a antiga sedentariedade", argumenta Virilio (1993, p. 11. Grifos do autor). De um lado, porque já não é assustador a convivência com toda sorte de limites impostos à trajetividade, e muitas vezes esses limites são clamados pela sociedade civil, em nome de algum princípio justificador, em nome de uma pretensa melhoria social. De outro lado, pelo fato de essa inércia produzir, cada vez mais, uma percepção uniformizada sobre os sentidos por intermédio da padronização de signos materiais. Os espaços tornaram-se, assim, verdadeiras experiências de consumo e, como é peculiar à lógica do consumo, as coisas só têm sentido até o instante em que são consumidas.

Se não é possível desmantelar a atual máquina sedentária por completo, na mesma proporção que não é possível saber como ela foi montada, ao menos é plausível convocar signos da arte para potencializar tensões em suas engrenagens. E a questão fundamental, nesse horizonte, está na alteração do regime de percepção dos sujeitos que convivem e coexistem com a trajetividade sedentarizada, com espaços inertes e com um mundo unificado pelas regras e pelos limites da homotopia. Nessa dimensão não há receitas, pois qualquer uma já pressuporia um dever à trajetividade de um sujeito. Mas não seria o cinema uma experiência de deslizamento por onde a percepção com a heterotopia e com o nomadismo poderia ocorrer de modo dinâmico? No cinema não são as paredes que determinam a relação com o espaço, mas as cenas projetadas na tela, o fantástico como questionamento do real, a instilação da memória sobre o peso do esquecimento, a ampliação dos limites dos afetos, provocando um transbordamento na captura dos signos paralizantes. Não seria o cinema uma máquina de guerra contra a máquina sedentária? Ou não seria o cinema uma experiência de um outro devir máquina nômade?

Sob as ações indeterminadas, os limites, o apagamento da memória, as regras impostas para uma obediência servil, em nome da igualdade, as comunidades de The giver, em um ponto determinado do filme, acabam por experimentar uma coloração distinta da sépia padrão inicial. Mas tal fato só foi possível no instante que algo escorreu para fora dos limites impostos, deslizou-se, provocando uma heterotopia.

\section{Corta! Em busca de outras Cenas.}

Deleuze (2009), ao remarcar a diferença entre o cinema clássico e o moderno, enfatizava $o$ aspecto singular de que a imagem sonora não mais se subordinava à imagem visual. É assim, por exemplo, que a voz em off de The giver anuncia algo completamente 
descolado da realidade mostrada. Entre o visível e o enunciado, o cinema, por ser signo da arte, permite ao visível não ser reduzido a um enunciado, justamente por fazer emergir o diferencial como trama relacional ou trama a ser relacionada entre $o$ que está para acontecer, o enunciado e a extração da experiência singular entre acontecimento e enunciado. No limite, o cinema é um agenciamento de inserção na diferença perceptorial dos sujeitos. Eis Deleuze (2010, p. 39. Grifos do autor) recordando Proust: "diferença qualitativa decorrente da maneira pela qual encaramos o mundo, diferença que, sem a arte, seria o eterno segredo de cada um de nós".

Se a trajetividade e a heterotopia tendem a ser estancadas pela máquina de sedentarismo, a arte do cinema seria um elemento fundamental na produção de experiências que buscam ir além dos agentes indeterminados presentes no mapeamento e nas conexões dos fluxos heterotópicos. Fluxos que visam à explosão lógico-coerente de seus limites, que criam fronteiras percepto-afetivas no ir e vir; fluxos que se contrapõem à dissolução da heterotopia, fazendo que os sujeitos não se experimentem na coextensão de suas diferentes trajetividades, passando por elas sem deixarem ser tocados por suas cores e dimensões, notadamente na vertiginosa velocidade das sociedades de hiper-dispersão. E nesse caso, vale lembrar os termos de Paul Morand, citados por Virilio (1993, p. 116) "a velocidade mata a cor: quando o giroscópio gira rapidamente, ele produz o cinza”. Mas isso não é tudo, ainda restam as regras e a obediência a fim de planificarem as experiências de trajetividade, reduzindo-as em homotopias ou em sensações habitáveis, desviando os sujeitos de qualquer heterotopia que seria capaz de fazê-los "entrar em contato com um mundo para o qual não fomos feitos" (PROUST, 1958, p. 201).

Quais experiências de trajetividade são possíveis de serem apreendidas em um filme? Como "ler" um filme para além da máquina sedentária? Como ser com o filme para produzir outra máquina nômade? Tais questões são chaves de penetração no cinema como signo da arte a fim de produzir diferenças. Mas também são agenciamentos relacionais com a nossa constituição de subjetividade. "O que é uma essência, tal como é revelada na obra de arte? É uma diferença, a Diferença última e absoluta. É ela que constitui o ser, que nos faz concebê-lo" (DELEUZE, 2010, p. 39).

A constituição desse ser como e para a diferença é o desafio maior que se impõe na produção de outra máquina de produção de subjetividade. Outra porque, se é fato que o cinema pode potencializar outras experiências percepto-afetivas com a trajetividade e com a heterotopia, é certo que tais experiências também podem igualmente ser desdobradas na hipótese proustiana. Quer dizer, não se trata mais 
de aceitar a mesma trajetividade sedentária inercial ou o bloqueio das heterotopias, mas de nos abrimos às cenas que não repõem nada, de ultrapassar os nossos muros, como Omar, de sair da imposição dos sujeitos indeterminados, como em The Giver. Cortar, cortar e outra vez cortar a homotopia, a cena de congelamento da subjetividade sedentária para, enfim, nos deslizar no mundo, sorvendo a heterotopia e a trajetividade como quem é capaz de sorver a vida numa obra de $a^{2}{ }^{2}$.

\section{REFERÊNCIAS}

ARENDT, H. Entre o passado e o futuro. Trad: Mauro W. Barbosa. São Paulo: Perspectiva, 2007.

CARVALHO, A. F. de; CAMARGO, A. C. de. Guattari e a topografia da máquina escolar. Revista Educação Temática Digital - ETD, v. 17, n. 1, , p. 107-124, 2015.

DELEUZE, G. A imagem tempo:cinema 2. Trad. Eloisa de Araujo Ribeiro. São Paulo: Brasiliense, 2009. . Prouste os signos. Trad. Antonio Piquet e Roberto Machado. Rio de Janeiro: GEN; Forense

Universitária, 2010. .El poder: curso sobre Foucault. Buenos Aires: Cactus Editorial, 2014. . GUATTARI, F. O anti-édipo. Trad. Luiz B. L. Orlandi. São Paulo: Editora 34, 2010. . Lignes de fuite: pour un autre monde de possibles. La Tours d'Aigues: L’aube, 2011. . L'inconscient machinique: essais de schizo-analyse. Paris: Éditions Recherche, $2011 \mathrm{~b}$.

FOUCAULT, M. Les corps utopiques, les hétérotopies. Clamecy: Lignes, 2010.

GUATTARI, F. Caosmose: um novo paradigma estético. Trad. Ana Lucia de Oliveira e Leticia Claudia Leão. São Paulo: Editora 34, 1992.

PROUST, M. Em busca do tempo perdido. v. 1. No caminho de Swann. Rio de Janeiro, Porto Alegre, São Paulo: Globo, 1958.

RAMOS, G. Angústia. São Paulo: Biblioteca Folha, 2003.

VIRILIO, Paul. O espaço crítico. Trad. Paulo Roberto Pires. São Paulo: Editora 34, 1993.

\section{Filmografia}

O DOADOR de memórias. Direção de Phillip Noyce. [s.i.] EUA: Twc/waldem Media, 2013. (97 $\min$.), som, cor.

OMAR. Direção de Hany Abu-assad. [s.i.] Palestina: AdoptFilms, 2013. (10o min.), P\&B.

2. Dois textos meus estão presentes direta ou indiretamente na composição de toda esta escrita: "Foucault e as infâncias incendiárias: experiências de outras verdades e de outras heterotopias”, publicado em Chilhood $\hookleftarrow$ Philosophy, v. 12, n. 23 (2016); “Trajetividade e máquina geográfica: cinema e terras entre intervalos para outros espaços sem terra”, publicado em Intervalo II - Entre Geografias e Cinemas. Ana Francisca de Azevedo; Rosa Cerarols Ramirez; Wenceslao Machado de Oliveira Jr. (Org.). Minho/Braga: UMDGEO, 2015. Esta escrita compõe o corpus do projeto de pesquisa Filosofia das diferenças, transverão epistemológica e devir-outro, financiado pela Fundação de Amparo à Pesquisa do Estado de São Paulo (FAPESP - Processo 2016/o5440-7). 
Heterotopias e trajetividades: lugares para as diferenças nas subjetividades nômades

SOBRE O AUTOR

Alexandre Filordi de Carvalho é graduado em Pedagogia (Universidade Estadual de Campinas) e Mestre e Doutor em Educação pela mesma universidade. É também Doutor em Filosofia (Universidade de São Paulo). É professor associado da Universidade Federal de São Paulo, Campus de Guarulhos. Tem experiência na área da filosofia contemporânea e da filosofia da educação, com pesquisas nos seguintes temas: subjetividades e diferenças a partir dos pensamentos de Michel Foucault e de Félix Guattari.

E-mail: afilordi@gmail.com.

Recebido em 27 de janeiro de 2018 e aprovado em 22 de março de 2018. 